\title{
Highly Stereoselective Synthesis and Hydrogenation of (Z)-1-Alkyl-2- arylvinyl Acetates: a Wide Scope Procedure for the Preparation of Chiral Homobenzylic Esters
}

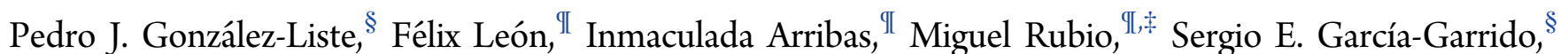
Victorio Cadierno, ${ }^{*}, \S$ and Antonio Pizzano ${ }^{*}, \mathbb{I}$

${ }^{\S}$ Laboratorio de Compuestos Organometálicos y Catálisis (Unidad Asociada al CSIC), Centro de Innovación en Química Avanzada (ORFEO-CINQA), Departamento de Química Orgánica e Inorgánica, Instituto Universitario de Química Organometálica "Enrique Moles”, Universidad de Oviedo, 33006 Oviedo, Spain

II Instituto de Investigaciones Químicas and Centro de Innovación en Química Avanzada (ORFEO-CINQA), CSIC and Universidad de Sevilla, 41092 Sevilla, Spain

\section{Supporting Information}

ABSTRACT: A synthesis of (Z)-1-alkyl-2-arylvinyl acetates 3 with broad scope is reported by using two complementary methods. The first one uses a stereospecific gold-catalyzed addition of acetic acid to 1-iodo-alkynes, followed by a Suzuki coupling. By the second, 1-methyl-2-arylvinyl substrates have been obtained selectively as the $Z$ isomers by $O$-acylation of enolates of methyl benzyl ketones. In addition, the asymmetric hydrogenation of enol esters 3 has been covered for the first time. Using rhodium catalysts based on chiral phosphinephosphite ligands (P-OP), highly enantioselective hydrogenations (up to $99 \%$ ee) have been achieved for a wide range of substrates. Thus, the synthesis and enantioselective hydrogenation of 3 provides a convenient and versatile procedure for the synthesis of valuable chiral homobenzylic esters.

KEYWORDS: iodo-alkenes, enol esters, asymmetric hydrogenation, chiral esters, $\mathrm{Rh}$ catalysts nantiopure homobenzylic alcohols (A in Scheme 1) form a
pivotal class of building blocks in organic synthesis, useful

Scheme 1. Structures of Compounds A-E

$$
\underbrace{R}_{A k=a l k y l, A r=A r y l ;}=A k, A r
$$

for the preparation of diverse types of compounds like aryl-2propylamines, chromenes, or benzofurans, among others, ${ }^{1}$ which notably include some pharmaceutical products. ${ }^{2}$ With respect to this importance, the synthesis of compounds $\mathbf{A}$ has thoroughly been investigated. ${ }^{3}$ In this regard, it is particularly remarkable that a procedure based on an enantioselective catalytic diboration of terminal alkenes, followed by a crosscoupling step, has been described by the group of Morken, which provide a broad range of alcohols with high enantioselectivity. ${ }^{4}$ Moreover, because of efficiency and practical advantages, the enzymatic reduction of benzyl alkyl ketones $\mathbf{B}$ has also received great attention. ${ }^{5}$ By using this procedure, diverse alcohols A have been obtained with exceedingly high enantioselectivity. However, most of these alcohols are methyl carbinols, while information about the

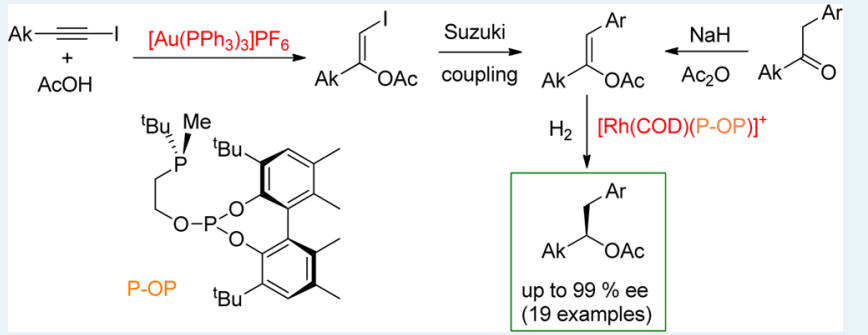

reduction of ketones with alkyl (Ak) substituents other than $\mathrm{Me}$ is rather scarce. ${ }^{6}$ This factor can be of high importance because of the influence of the $\mathrm{Ak}$ substituent on the enantioselectivity observed in some of these enzymatic reactions. $^{6 a}$

The success of the enzymatic reduction of $\mathbf{B}$ strongly contrasts with the results obtained in catalytic asymmetric hydrogenations. Thus, only rare examples of this reaction have been reported in the literature, which in addition, show low to moderate enantioselectivity (up to $85 \%$ ee). ${ }^{7}$ Nevertheless, the group of Xiao has reported a highly enantioselective ( $98 \%$ ee) transfer hydrogenation of 3-trifluoromethylphenyl-propan-2one, but no information about a further scope of the corresponding catalytic system was provided. ${ }^{8}$

An alternative route to alcohols $\mathbf{A}$ based on an asymmetric hydrogenation, which could also benefits of the inherent practical advantages of this kind of reaction, ${ }^{9}$ is based on the reduction of the olefin bond of 1-alkyl-2-arylvinyl esters $\mathbf{C}$ followed by a trivial deacylation. ${ }^{9 \mathrm{~g}, 1,10 a, 11}$ In a previous contribution, we described the highly enantioselective hydrogenation of 1-benzylvinyl benzoate (D), but extension of this

Received: January 28, 2016

Revised: $\quad$ March 29, 2016

Published: April 4, 2016 
reaction would only be suitable for the synthesis of methyl carbinol derivatives. ${ }^{10}$ Toward a more general method, we envisioned that the hydrogenation of $\mathbf{C}$ would be of substantially higher value. This reaction has not been reported before and represents a considerable challenge. ${ }^{12,13}$ The closer precedent is constituted by the Rh-catalyzed hydrogenation of 1-alkyl-2-methylvinyl esters reported by Gooßen and coworkers, which provided up to $98 \%$ ee for the 1 -Me substrate, whereas it decreased down to 82 and $78 \%$ ee for the corresponding $1-{ }^{\mathrm{n}} \mathrm{Pr}$ and $1-{ }^{\mathrm{n}} \mathrm{Bu}$ derivatives, respectively. ${ }^{14} \mathrm{In}$ this context, we now report a highly enantioselective catalytic system for the hydrogenation of $\mathbf{C}$ which operates under mild conditions, along with very convenient procedures for the synthesis of these substrates, which are selectively obtained as $Z$ isomers.

As a first stage, we investigated a wide scope synthesis for olefins $\mathbf{C}$ as reports on the preparation of these compounds are practically limited to 1-arylpropen-2-yl esters. ${ }^{15}$ Among different methods for the synthesis of enol-esters, ${ }^{16}$ the intermolecular catalytic addition of carboxylic acids to alkynes is a highly versatile and efficient procedure. ${ }^{17}$ However, application of this procedure to internal unactivated ${ }^{18}$ aryl-alkynes toward the synthesis of $\mathbf{C}$ is hampered by a difficult control of regioselectivity, as well as a biased addition of the carboxylic acid to the aryl bonded carbon giving opposed regioisomers. ${ }^{19,20}$ With the aim to circumvent these problems, an alternative procedure based on the unprecedented addition of carboxylic acids to 1-iodo-alkynes $\mathbf{1}$ has been developed. ${ }^{21}$ Thus, we found that gold(I)-catalyzed addition of $\mathrm{AcOH}$ to 1 proceeds with exquisite regio- and stereoselectivity, leading to the corresponding iodo-alkenes $\mathbf{2}$ as pure $Z$ isomers in good yields (76-90\%; Scheme 2). ${ }^{22}$ Subsequent arylation of

Scheme 2. Synthesis of Enol Esters 3a-3n (Isolated Yields for Two Steps in Brackets)

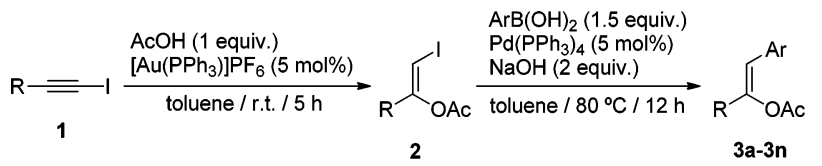

$$
\begin{aligned}
& \overbrace{R}^{\mathrm{Ph}} \begin{array}{l}
\mathrm{R}={ }^{\mathrm{n}} \operatorname{Pr}(\mathbf{3 a}, 57 \%){ }^{\mathrm{n}} \mathrm{Bu}(\mathbf{3 b}, 59 \%),{ }^{n} \mathrm{Pen}(\mathbf{3 c}, 63 \%), \\
{ }^{\mathrm{n}} \mathrm{Hex}(\mathbf{3 d}, 69 \%), \mathrm{CH}_{2} \mathrm{CH}_{2}{ }^{i} \operatorname{Pr}(\mathbf{3 e}, 58 \%),{ }^{c} \mathrm{C}_{3} \mathrm{H}_{5}(\mathbf{3 f}, 52 \%), \\
\mathrm{Cy}(\mathbf{3 g}, 55 \%)
\end{array} \\
& \int \begin{array}{ll}
\mathrm{Ar} & \mathrm{Ar}=4-\mathrm{F}-\mathrm{C}_{6} \mathrm{H}_{4}(3 \mathrm{~h}, 67 \%), 4-\mathrm{MeO}-\mathrm{C}_{6} \mathrm{H}_{4}(\mathbf{3 i}, 72 \%), 4-\mathrm{Me}_{4}-\mathrm{C}_{6} \mathrm{H}_{4} \\
(\mathbf{3 j}, 72 \%), 4-\mathrm{Cl}-\mathrm{C}_{6} \mathrm{H}_{4}(\mathbf{3 k}, 62 \%), 4-\mathrm{Ph}_{2}-\mathrm{C}_{6} \mathrm{H}_{4}(\mathbf{3 i}, 70 \%),
\end{array} \\
& 3,4-(\mathrm{MeO})_{2}-\mathrm{C}_{6} \mathrm{H}_{3}(3 \mathrm{~m}, 72 \%), 3,5-(\mathrm{MeO})_{2}-\mathrm{C}_{6} \mathrm{H}_{3}(3 \mathrm{n}, 62 \%)
\end{aligned}
$$

compounds 2 allowed us to reach a wide range of enol esters $3 a-3 n$, differing in the nature of the $\mathrm{R}$ and Ar groups (52-72\% overall yields from 1, Scheme 2). From a practical viewpoint, it is also worthwhile to recall that these substrates are prepared as configurationally pure $Z$ isomers, thus avoiding a tedious separation of olefin isomers before hydrogenation. An extension of the present method to the synthesis of 1methylvinyl esters would require a cumbersome deprotonation of propyne and handling of relatively volatile 1-iodopropyne (bp $110^{\circ} \mathrm{C}$ ). As these enol esters have a great interest because they can provide a convenient access to methyl carbinols useful in the synthesis of biologically active compounds, ${ }^{23}$ we have investigated a more practical synthesis starting from commercially available benzyl methyl ketones (Scheme 3). First, reaction of $p$-methoxyphenyl acetone with isopropenyl acetate, in the presence of a catalytic amount of $p$-toluenesulfonic acid,
Scheme 3. Synthesis of Enol Esters 3o-3s (Isolated Yields in Brackets)

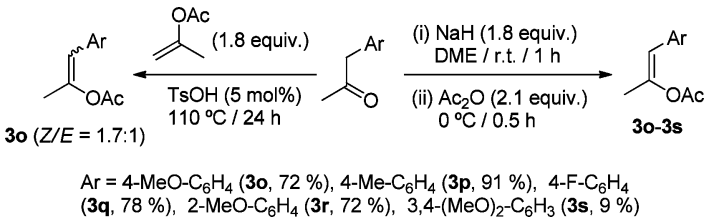

produced enol ester 3o as a $Z / E$ 1.7:1 mixture. Due to difficult isomer separation, ${ }^{24}$ we alternatively investigated the acylation of the corresponding enolate. ${ }^{25}$ This route satisfyingly produced 30 in high yield as a $Z / E$ 97:3 mixture. Using this procedure, $Z$ isomers of compounds $3 p-3 s$ were also obtained with high selectivity (96-99\%) and generally good yields (72$91 \%)$, with the exception of 3 s for which a low yield was obtained. $^{26}$

For hydrogenation studies a set of catalyst precursors bearing phosphine-phosphite ligands (P-OP) of general formula $[\mathrm{Rh}($ diolefin $)(\mathrm{P}-\mathrm{OP})] \mathrm{BF}_{4}$ [diolefin =1,4-norbornadiene, P-OP $=5 \mathrm{a}-5 \mathrm{c}(6 \mathrm{a}-6 \mathrm{c}) ; 1,5-c y c l o o c t a d i e n e$, P-OP $=5 \mathrm{~d}-5 \mathrm{e}(6 \mathrm{~d}-$ 6e)] were used (Chart 1$).{ }^{10}$ It is worthy of noting that the set

Chart 1. Chiral Ligands Used in the Present Study
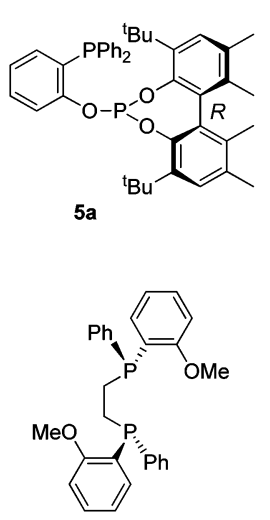

$(R, R)$-DiPAMP

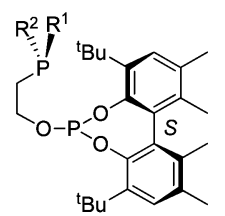

$\mathrm{R}^{1}=\mathrm{R}^{2}=\mathrm{Ph}(\mathbf{5 b}), p$-tolyl $(5 \mathrm{c})$ $\mathrm{R}^{1}=\mathrm{Me}, \mathrm{R}^{2}={ }^{\mathrm{t}} \mathrm{Bu}(\mathbf{5 d})$

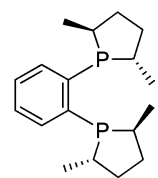

$(S, S)$-Me-DuPHOS

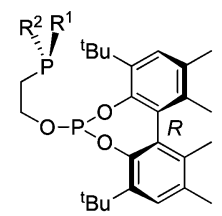

$R^{1}=M e, R^{2}={ }^{\mathrm{t}} \mathrm{Bu}(\mathbf{5 e})$

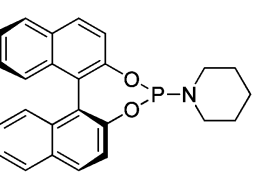

(S)-PipPHOS contains two novel diastereomeric catalyst precursors 6d-6e characterized by a highly basic $P$-stereogenic phosphine fragment and differing in the configuration of the phosphite one. These complexes were obtained from the corresponding phosphine-phosphites $\mathbf{5 d - 5 e , ~ w h i c h ~ w e r e ~ p r e p a r e d ~ f r o m ~}(S)$ tert-butyl-methyl-2-hydroxyethyl phosphine borane ${ }^{27}$ (see Supporting Information for details).

Among the different enol-esters synthesized, 3d was chosen as a representative one, and a set of hydrogenations (Scheme 4)

Scheme 4. Asymmetric Hydrogenation of Enol Esters 3

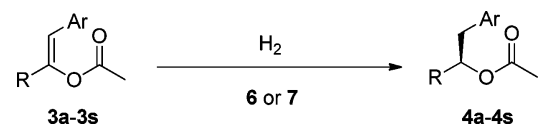

were prepared with it under mild conditions $\left(40{ }^{\circ} \mathrm{C}, 4\right.$ bar $\mathrm{H}_{2}$, $\mathrm{S} / \mathrm{C}=100, \mathrm{CH}_{2} \mathrm{Cl}_{2}$, Table 1$)$. These reactions evidenced a rather low reactivity of $3 \mathrm{~d}$. Thus, catalyst precursors $\mathbf{6 a}, \mathbf{6 b}$, and 6e showed low conversion values (entries $1,2,4)$. This is a remarkable difference with the hydrogenation of $\mathbf{D}$, as $\mathbf{6 a}$ and 6b typically provide complete conversion at $\mathrm{S} / \mathrm{C}=500$ under 
Table 1. Hydrogenation of $3 \mathrm{~d}$ Performed with $6-7^{a}$

\begin{tabular}{ccclcc} 
entry & cat. & S/C & \multicolumn{1}{c}{ solvent } & \% conv. & \% ee (conf) \\
\hline 1 & 6a & 100 & $\mathrm{CH}_{2} \mathrm{Cl}_{2}$ & 13 & nd \\
2 & 6b & 100 & $\mathrm{CH}_{2} \mathrm{Cl}_{2}$ & $<5$ & nd \\
3 & 6d & 100 & $\mathrm{CH}_{2} \mathrm{Cl}_{2}$ & 79 & $98(S)$ \\
4 & 6e & 100 & $\mathrm{CH}_{2} \mathrm{Cl}_{2}$ & 38 & $94(R)$ \\
5 & 6d & 100 & $\mathrm{DCE}^{2}$ & $>99$ & $98(S)$ \\
6 & 6d & 100 & toluene & $<5$ & nd \\
7 & 6d & 100 & $2-\mathrm{Me}-\mathrm{THF}$ & 37 & $77(S)$ \\
8 & 6d & 100 & i $\mathrm{PrOH}$ & 77 & $79(S)$ \\
9 & 6d & 250 & DCE & 98 & $98(S)$ \\
10 & 6d & 500 & DCE & 41 & $98(S)$ \\
11 & 7a & 100 & DCE & 57 & $93(R)$ \\
12 & 7b & 100 & DCE & 61 & $45(R)$ \\
13 & 7c & 100 & DCE & 13 & $16(S)$
\end{tabular}

${ }^{a}$ Hydrogenations under 4 bar $\mathrm{H}_{2},[\mathrm{Rh}]=2 \times 10^{-4} \mathrm{M},[3 \mathrm{~d}]=0.02-$ $0.10 \mathrm{M}$, at $40{ }^{\circ} \mathrm{C}$ for $24 \mathrm{~h}$, unless otherwise stated. Conversion determined by ${ }^{1} \mathrm{H}$ NMR and \% ee by chiral HPLC. See Supporting Information for determination of configuration.

these reaction conditions. ${ }^{10}$ In contrast, complex $6 \mathrm{~d}$ offered a great improvement on catalyst activity, also providing a very high enantioselectivity ( $98 \%$ ee, entry 3). Notably, an important influence of the solvent in performance of $\mathbf{6 d}$ was observed (entries 5-8), which allowed us to complete the reaction in 1,2-dichloroethane (DCE) with high enantioselectivity ( $98 \%$ ee). Considering that several ( $Z$ )-3-aryl-2acyloxyacrylates have been hydrogenated under mild conditions with very high enantioselectivity ( $>95 \%$ ee, $3-5$ bar $\mathrm{H}_{2}$, rt) using commercially available Me-DuPHOS ${ }^{13 a}$ and DiPAMP ${ }^{9 b, k}$ catalysts, it looks of interest to test these catalysts in the hydrogenation of $\mathbf{3 d}$ under the optimized conditions. Thus, $[\mathrm{Rh}(\mathrm{COD})(S, S)-\mathrm{Me}-\mathrm{DuPHOS}] \mathrm{BF}_{4}$ (7a) provided a moderate conversion albeit with a high enantioselectivity $(57 \%, 93 \%$ ee, entry 11$)$. On the other hand, $[\mathrm{Rh}(\mathrm{COD})(R, R)-\mathrm{DiPAMP}] \mathrm{BF}_{4}$ (7b) provided only moderate conversion and enantioselectivity (entry 12). For comparison, the catalyst prepared in situ from $\left[\mathrm{Rh}(\mathrm{COD})_{2}\right] \mathrm{BF}_{4}$ and 2 equiv of phosphoramidite $(S)$ PipPHOS (7c) $)^{94,13 b}$ was also tested. It showed both low conversion and enantioselectivity (entry 13). This comparison indicates a particular suitability of $\mathbf{6 d}$ for the present hydrogenation. Finally, lowering of the catalyst loading still showed a satisfactory performance at $\mathrm{S} / \mathrm{C}=250$ (entry 9), while conversion sharply decreased at $\mathrm{S} / \mathrm{C}=500$ (entry 10).

In a next stage, the scope of the best catalytic system (i.e., that based on complex $\mathbf{6 d}$ in DCE) was then examined. As observed in the hydrogenation of $\mathbf{3 d}$, substrates bearing a primary alkyl $\mathrm{R}$ substituent (3a-3c, 3e) provided full conversion and high enantioselectivity (94-98\% ee, entries $1-5$ in Table 2). Under the standard conditions, cyclopropyl substrate $3 \mathrm{f}$ provided full conversion and only $77 \%$ ee (entry 6). However, an important enhancement on enantioselectivity up to $92 \%$ ee (entry 7) was observed when the reaction was performed at $30{ }^{\circ} \mathrm{C} .{ }^{28}$ Disappointingly, the cyclohexyl substrate $3 \mathrm{~g}$ showed low reactivity either using $\mathbf{6 d}$ or $\mathbf{6 c}$ under 4 bar $\mathrm{H}_{2}$, with conversion values of 18 and $7 \%$, respectively (entries 8 and 9). Use of $6 \mathbf{d}$ under 20 bar $\mathrm{H}_{2}$, increased the conversion up to $50 \%$ in $48 \mathrm{~h}$, although enantioselectivity was only moderate (47\% ee, entry 10). Apparently, the steric hindrance introduced by the cyclohexyl substituent is detrimental for both catalyst activity and enantioselectivity, constituting a limitation for the present catalytic system.
Table 2. Hydrogenation of $3 a-3 n$ Performed with $6 d^{a}$

\begin{tabular}{|c|c|c|c|c|}
\hline entry & substrate & $\mathrm{H}_{2}$ (bar) & $\%$ conv. & $\%$ ee (conf.) \\
\hline 1 & $3 a$ & 4 & $>99$ & $94(S)$ \\
\hline 2 & $3 \mathbf{b}$ & 4 & $>99$ & $98(S)$ \\
\hline 3 & $3 \mathrm{c}$ & 4 & $>99$ & $98(S)$ \\
\hline 4 & $3 d$ & 4 & $>99$ & $98(S)$ \\
\hline 5 & $3 e$ & 4 & $>99$ & $97(S)$ \\
\hline 6 & $3 f$ & 4 & $>99$ & 77 (nd) \\
\hline $7^{b}$ & $3 f$ & 4 & $>99$ & $92(\mathrm{nd})$ \\
\hline 8 & $3 g$ & 4 & 18 & nd \\
\hline $9^{c}$ & $3 g$ & 4 & 7 & nd \\
\hline $10^{d}$ & $3 g$ & 20 & 50 & 47 (nd) \\
\hline 11 & $3 \mathrm{~h}$ & 4 & $>99$ & $96(S)$ \\
\hline 12 & $3 \mathbf{i}$ & 4 & 83 & $95(S)$ \\
\hline 13 & $3 \mathbf{j}$ & 4 & 94 & $97(S)$ \\
\hline 14 & $3 k$ & 4 & $>99$ & $95(S)$ \\
\hline 15 & 31 & 4 & $>99$ & $96(S)$ \\
\hline 16 & $3 m$ & 4 & $<5$ & nd \\
\hline 17 & $3 n$ & 4 & $>99$ & $96(S)$ \\
\hline $18^{e}$ & $3 \mathbf{i}$ & 4 & $>99$ & $95(S)$ \\
\hline 19 & $3 \mathbf{j}$ & 20 & $>99$ & $93(S)$ \\
\hline 20 & $3 m$ & 20 & $>99$ & $95(S)$ \\
\hline
\end{tabular}

${ }^{a}$ Hydrogenations performed at $40{ }^{\circ} \mathrm{C}$ in DCE for $24 \mathrm{~h}$ at $\mathrm{S} / \mathrm{C}=100$; $[\mathrm{Rh}]=2 \times 10^{-4} \mathrm{M},[3]=0.02 \mathrm{M}$, unless otherwise stated. Conversion determined by ${ }^{1} \mathrm{H}$ NMR and \% ee by chiral HPLC. See Supporting Information for determination of configuration. ${ }^{b}$ Reaction performed at $30^{\circ} \mathrm{C}$. ${ }^{c}$ Reaction performed with 6 c. $^{d} 48 \mathrm{~h}$ reaction time. ${ }^{e}[\mathrm{Rh}]=4$ $\times 10^{-4} \mathrm{M},[3 \mathbf{i}]=0.04 \mathrm{M}$.

Substrates with diverse aryl substituents were next examined. Thus, for a set of enol esters bearing a 1-hexyl substituent (3h3n), outstanding enantioselectivities were generally observed under our standard conditions (95-97\% ee, entries 11-15, 17). In addition, conversion was largely high, except in the case of 3,4-dimethoxy substrate $3 \mathrm{~m}$, for which no reactivity was observed under 4 bar $\mathrm{H}_{2}$ (entry 16). In contrast, a complete reaction with a high enantioselectivity could be obtained under 20 bar $\mathrm{H}_{2}$ (95\% ee, entry 20). Moreover, hydrogenations of 3i and $3 \mathbf{j}$ could be forced to completion, without a significant decrease in enantioselectivity, by using a higher substrate concentration (entry 18) or higher pressure (entry 19), respectively.

On the other hand, hydrogenation of 3o with complex $6 \mathrm{~d}$ produced a lower enantioselectivity than previous examples (91\% ee, entry 1, Table 3) and some other catalyst precursors

\section{Table 3. Hydrogenation of 3o-3s Performed with} Complexes $6^{a}$

\begin{tabular}{|c|c|c|c|c|}
\hline entry & substrate & cat. prec. & $\%$ conv. & $\%$ ee (conf.) \\
\hline 1 & 30 & $6 d$ & $>99$ & $91(S)$ \\
\hline 2 & 30 & $6 a$ & 62 & $80(R)$ \\
\hline 3 & 30 & $6 b$ & 84 & $95(S)$ \\
\hline 4 & 30 & $6 c$ & $>99$ & $97(S)$ \\
\hline 5 & $3 p$ & $6 c$ & 76 & $93(S)$ \\
\hline 6 & $3 q$ & $6 c$ & $>99$ & $98(S)$ \\
\hline 7 & $3 r$ & $6 c$ & $>99$ & $99(S)$ \\
\hline 8 & $3 s$ & $6 c$ & 59 & $87(S)$ \\
\hline $9^{b}$ & $3 p$ & $6 c$ & $>99$ & $91(S)$ \\
\hline 10 & $3 s$ & $6 d$ & $>99$ & $93(S)$ \\
\hline
\end{tabular}

${ }^{a}$ Reaction conditions and analysis as described in footnote a of Table 2. ${ }^{b}$ Reaction prepared under 10 bar $\mathrm{H}_{2}$. 
were tested (entries 2-4). Among them, $6 \mathrm{c}$ provided the most satisfactory results with full conversion and very high enantioselectivity ( $97 \%$ ee, entry 4 ). For comparison, the hydrogenation of a $Z / E$ 1.7:1 mixture of 30 was also examined with some of these catalysts. Thus, $\mathbf{6 a}, \mathbf{6 b}$, and $\mathbf{6 d}$ gave enantioselectivities of 58,80 , and $44 \%$ ee, respectively. These values account for a decrease between 15 and $47 \%$ ee, with respect to corresponding hydrogenations of the pure $Z$ isomer and demonstrate a high influence of the ratio of olefin isomers on enantioselectivity. Most importantly, these data indicate that the synthetic procedures provided herein for enol esters 3 perfectly match the requirements for Rh-catalyzed asymmetric hydrogenation. It is also pertinent to note that a critical influence of olefin configuration on enantioselectivity has been reported by the groups of Zhang ${ }^{12 a}$ and Zhou ${ }^{12 b}$ in the hydrogenation of $\beta$-aryl enamides $\mathbf{E}$.

Catalyst precursor $6 \mathrm{c}$ was next applied in the hydrogenation of substrates $3 \mathbf{p}-3 \mathbf{s}$, differing in the nature of the aryl substituent. In general, a good catalytic performance was observed in these reactions, with good to quantitative conversion and enantioselectivities ranging between 93 and 99\% ee (entries 5-7). However, for $p$-tolyl substrate 3p, an uncompleted reaction (76\%, entry 5) with $93 \%$ ee was observed. An increase in pressure up to 10 bar $\mathrm{H}_{2}$ afforded full conversion and a slight decrease in enantioselectivity (91\% ee, entry 9). An exception to this behavior is constituted by the 3,4-dimethoxyphenyl substrate 3s, which showed a lower enantioselectivity (87\% ee, entry 8 ) and displayed a moderate conversion (59\%) using catalyst precursor $\mathbf{6 c}$. This effect may be related with the low reactivity shown by $3 \mathrm{~m}$ and suggests a competitive $k^{2}(O, O)$-coordination of the 3,4-dimethoxyphenyl fragment to the $\mathrm{Rh}$ center. For substrate $3 \mathrm{~s}$, complex $\mathbf{6 d}$ provided full conversion and good enantioselectivity (93\% ee, entry 10). Finally, it is worthwhile to recall that some of the highly enantioenriched esters 4 have a considerable synthetic interest. For instance, $4 \mathbf{n}$ can be a convenient precursor for the synthesis of Berkelic acid, ${ }^{1 e, 3 b}$ while $4 s$ has been applied in the synthesis of benzodiazepines ${ }^{23 c}$ and chromanes. ${ }^{23 \mathrm{e}}$

In conclusion, a convenient and broad-scope procedure for the synthesis of valuable chiral homobenzylic esters has been described. The reaction sequence is based on an unprecedented stereospecific gold-catalyzed addition of acetic acid to 1-iodoalkynes as well as on a highly enantioselective hydrogenation of (Z)-1-alkyl-2-arylvinyl acetates 3, which is also covered for the first time. These results point to the feasibility of the hydrogenation of other trisubstituted enol esters and research to broaden the scope of this protocol is currently underway.

\section{ASSOCIATED CONTENT}

\section{S Supporting Information}

The Supporting Information is available free of charge on the ACS Publications website at DOI: 10.1021/acscatal.6b00282.

Full characterization of new compounds (PDF)

\section{AUTHOR INFORMATION}

\section{Corresponding Authors}

*E-mail: vcm@uniovi.es (V.C.).

*E-mail: pizzano@iiq.csic.es (A.P.).

\section{Present Address}

‡(M.R.) Repsol Technology Center, 28931 Móstoles, Madrid, Spain.

\section{Notes}

The authors declare no competing financial interest.

\section{ACKNOWLEDGMENTS}

MINECO (projects CTQ2013-42501-P, CTQ2013-40591-P and CTQ2014-51912-REDC) of Spain and the Government of the Principality of Asturias (project GRUPIN14-006) are acknowledged for financial support. Mass Spectrometry Service of Universidad de Sevilla (CITIUS) is acknowledged for technical assistance.

\section{REFERENCES}

(1) (a) Uchida, K.; Watanabe, H.; Kitahara, T. Tetrahedron 1998, 54, 8975-8984. (b) Kerti, G.; Kurtán, T.; Illyés, T.-Z.; Kövér, K. E.; Sólyom, S.; Pescitelli, G.; Fujioka, N.; Berova, N.; Antus, S. Eur. J. Org. Chem. 2007, 2007, 296-305. (c) Carosi, L.; Hall, D. G. Can. J. Chem. 2009, 87, 650-661. (d) Chang, H.-S.; Lin, Y.-J.; Lee, S.-J.; Yang, C.W.; Lin, W.-Y.; Tsai, I.-L.; Chen, I.-S. Phytochemistry 2009, 70, 20642071. (e) Wu, X.; Zhou, J.; Snider, B. B. Angew. Chem., Int. Ed. 2009, 48, 1283-1286. (f) Mangas-Sánchez, J.; Busto, E.; Gotor-Fernández, V.; Gotor, V. Org. Lett. 2010, 12, 3498-3501. (g) Zhang, J.; Wang, H.; Ma, Y.; Wang, Y.; Zhou, Z.; Tang, C. Tetrahedron Lett. 2013, 54, 2261-2263. (h) Simon, R. C.; Busto, E.; Richter, N.; Belaj, F.; Kroutil, W. Eur. J. Org. Chem. 2014, 2014, 111-121.

(2) (a) Anderson, B. A.; Hansen, M. M.; Harkness, A. R.; Henry, C. L.; Vicenzi, J. T.; Zmijewski, M. J. J. Am. Chem. Soc. 1995, 117, 1235812359. (b) Acetti, D.; Brenna, E.; Fuganti, C. Tetrahedron: Asymmetry 2007, 18, 488-492. (c) Sawant, R. T.; Waghmode, S. B. Synth. Commun. 2010, 40, 2269-2277.

(3) For examples, see the following: (a) Kim, Y. H.; Park, D. H.; Byun, I. S.; Yoon, I. K.; Park, C. S. J. Org. Chem. 1993, 58, 4511-4512. (b) Snaddon, T. N.; Buchgraber, P.; Schulthoff, S.; Wirtz, C.; Mynott, R.; Fürstner, A. Chem. - Eur. J. 2010, 16, 12133-12140. (c) FernándezMateos, E.; Maciá, B.; Yus, M. Tetrahedron: Asymmetry 2012, 23, 789794.

(4) Mlynarski, S. N.; Schuster, C. H.; Morken, J. P. Nature 2014, 505, 386-390.

(5) (a) Erdélyi, B.; Szabó, A.; Seres, G.; Birincsik, L.; Ivanics, J.; Szatzker, G.; Poppe, L. Tetrahedron: Asymmetry 2006, 17, 268-274. (b) Musa, M. M.; Ziegelmann-Fjeld, K. I.; Vieille, C.; Zeikus, J. G.; Phillips, R. S. J. Org. Chem. 2007, 72, 30-34. (c) Salvi, N. A.; Chattopadhyay, S. Tetrahedron: Asymmetry 2011, 22, 1512-1515. (d) See also ref $1 \mathrm{~h}$

(6) (a) Vitale, P.; Perna, F. M.; Perrone, M. G.; Scilimati, A. Tetrahedron: Asymmetry 2011, 22, 1985-1993. (b) Patel, J. M.; Musa, M. M.; Rodriguez, L.; Sutton, D. A.; Popik, V. V.; Phillips, R. S. Org. Biomol. Chem. 2014, 12, 5905-5910.

(7) (a) Abdur-Rashid, K.; Amoroso, D.; Guo, R.; Chen, X.; Sui-Seng, C.; Tsang, C.-W.; Jia, W. (Kanata Chemical Technologies), WO 2009055912 A1, May 7, 2009. (b) Lagaditis, P. O.; Sues, P. E.; Sonnenberg, J. F.; Wan, K. Y.; Lough, A. J.; Morris, R. H. J. Am. Chem. Soc. 2014, 136, 1367-1380.

(8) Wu, X.; Li, X.; Zanotti-Gerosa, A.; Pettman, A.; Liu, J.; Mills, A. J.; Xiao, J. Chem. - Eur. J. 2008, 14, 2209-2222.

(9) For representative hydrogenations of enol esters, see: (a) Burk, M. J. J. Am. Chem. Soc. 1991, 113, 8518-8519. (b) Schmidt, U.; Langner, J.; Kirschbaum, B.; Braun, C. Synthesis 1994, 1994, 11381140. (c) Boaz, N. W. Tetrahedron Lett. 1998, 39, 5505-5508. (d) Jiang, Q.; Xiao, D.; Zhang, Z.; Cao, P.; Zhang, X. Angew. Chem., Int. Ed. 1999, 38, 516-518. (e) Tang, W.; Liu, D.; Zhang, X. Org. Lett. 2003, 5, 205-207. (f) Liu, Y.; Sandoval, C. A.; Yamaguchi, Y.; Zhang, X.; Wang, Z.; Kato, K.; Ding, K. J. Am. Chem. Soc. 2006, 128, 1421214213. (g) Vargas, S.; Suarez, A.; Alvarez, E.; Pizzano, A. Chem. - Eur. J. 2008, 14, 9856-9859. (h) Zhang, X.; Huang, K.; Hou, G.; Cao, B.; Zhang, X. Angew. Chem., Int. Ed. 2010, 49, 6421-6424. (i) Zupančič, B.; Mohar, B.; Stephan, M. Org. Lett. 2010, 12, 1296-1299. (j) NúñezRico, J. L.; Etayo, P.; Fernández-Pérez, H.; Vidal-Ferran, A. Adv. Synth. Catal. 2012, 354, 3025-3035. (k) Lüttenberg, S.; Ta, T. D.; von der 
Heyden, J.; Scherkenbeck, J. Eur. J. Org. Chem. 2013, 2013, 18241830. (1) Konrad, T. M.; Schmitz, P.; Leitner, W.; Franciò, G. Chem. Eur. J. 2013, 19, 13299-13303.

(10) (a) Kleman, P.; González-Liste, P. J.; García-Garrido, S. E.; Cadierno, V.; Pizzano, A. Chem. - Eur. J. 2013, 19, 16209-16212.

(b) Kleman, P.; González-Liste, P. J.; García-Garrido, S. E.; Cadierno, V.; Pizzano, A. ACS Catal. 2014, 4, 4398-4408.

(11) For the enantioselective hydrogenation of enol esters using a combination of Shvo complex and a lipase as catalysts, see: (a) Jung, H. M.; Koh, J. H.; Kim, M.-J.; Park, J. Org. Lett. 2000, 2, 409-411. (b) Jung, H. M.; Koh, J. H.; Kim, M.-J.; Park, J. Org. Lett. 2000, 2, 2487-2490.

(12) The hydrogenation of $\beta$-aryl enamides $\mathbf{E}$ is a very demanding process for which only some outstanding catalysts have provided satisfactory results: (a) Chen, J.; Zhang, W.; Geng, H.; Li, W.; Hou, G.; Lei, A.; Zhang, X. Angew. Chem., Int. Ed. 2009, 48, 800-802. (b) Zhu, S.-F.; Liu, T.; Yang, S.; Song, S.; Zhou, Q.-L. Tetrahedron 2012, 68, 7685-7690. (c) Liu, G.; Liu, X.; Cai, Z.; Jiao, G.; Xu, G.; Tang, W. Angew. Chem., Int. Ed. 2013, 52, 4235-4238.

(13) Enol esters are typically less reactive than enamides toward hydrogenation: (a) Burk, M. J.; Kalberg, C. S.; Pizzano, A. J. Am. Chem. Soc. 1998, 120, 4345-4353. (b) Panella, L.; Feringa, B. L.; de Vries, J. G.; Minnaard, A. J. Org. Lett. 2005, 7, 4177-4180. (c) Arribas, I.; Rubio, M.; Kleman, P.; Pizzano, A. J. Org. Chem. 2013, 78, 39974005.

(14) Mamone, P.; Grünberg, M. F.; Fromm, A.; Khan, B. A.; Gooßen, L. J. Org. Lett. 2012, 14, 3716-3719.

(15) (a) Uemura, S.; Tara, H.; Okano, M.; Ichikawa, K. Bull. Chem. Soc. Jpn. 1974, 47, 2663-2671. (b) Noyori, R.; Nishida, I.; Sakata, J. J. Am. Chem. Soc. 1983, 105, 1598-1608. (c) Nishiguchi, I.; Oki, T.; Hirashima, T.; Shiokawa, J. Chem. Lett. 1991, 20, 2005-2008. (d) Lee, P. H.; Kang, D.; Choi, S.; Kim, S. Org. Lett. 2011, 13, 3470-3473.

(16) For some representative examples, see: (a) Yu, J.-Y.; Shimizu, R.; Kuwano, R. Angew. Chem., Int. Ed. 2010, 49, 6396-6399. (b) Peralta-Hernández, E.; Blé-González, E. A.; Gracia-MedranoBravo, V. A.; Cordero-Vargas, A. Tetrahedron 2015, 71, 2234-2240. (c) See also ref $9 b$.

(17) For selected reviews on this transformation, see: (a) Alonso, F.; Beletskaya, I. P.; Yus, M. Chem. Rev. 2004, 104, 3079-3160. (b) Gooßen, L. J.; Rodríguez, N.; Gooßen, K. Angew. Chem., Int. Ed. 2008, 47, 3100-3120. (c) Hintermann, L. Top. Organomet. Chem. 2010, 31, 123-155. (d) Bruneau, C. Top. Organomet. Chem. 2011, 43, 203-230.

(18) For the addition to activated substrates such as alkynylcarboxylates, -amides, or -ethers, see: (a) Kita, Y.; Akai, S.; Ajimura, N.; Yoshigi, M.; Tsugoshi, T.; Yasuda, H.; Tamura, Y. J. Org. Chem. 1986, 51, 4150-4158. (b) Lu, X.; Zhu, G.; Ma, S. Tetrahedron Lett. 1992, 33, 7205-7206. (c) Menashe, N.; Shvo, Y. J. Org. Chem. 1993, 58, 74347439. (d) Wakabayashi, T.; Ishii, Y.; Murata, T.; Mizobe, Y.; Hidai, M. Tetrahedron Lett. 1995, 36, 5585-5588. (e) Smith, D. L.; Goundry, W. R. F.; Lam, H. W. Chem. Commun. 2012, 48, 1505-1507. (f) Yin, J.; Bai, Y.; Mao, M.; Zhu, G. J. Org. Chem. 2014, 79, 9179-9185.

(19) (a) Rotem, M.; Shvo, Y. J. Organomet. Chem. 1993, 448, 189204. (b) Chary, B. C.; Kim, S. J. Org. Chem. 2010, 75, 7928-7931. (c) Tsukada, N.; Takahashi, A.; Inoue, Y. Tetrahedron Lett. 2011, 52, 248-250. (d) Kawatsura, M.; Namioka, J.; Kajita, K.; Yamamoto, M.; Tsuji, H.; Itoh, T. Org. Lett. 2011, 13, 3285-3287.

(20) Recently, Nolan and co-workers have described a gold catalyst capable to selectively provide the desired regiochemistry in internal aryl alkynes: Dupuy, S.; Gasperini, D.; Nolan, S. P. ACS Catal. 2015, 5, 6918-6921.

(21) For a related hydrophosphoryloxylation process of 1-iodoalkynes, see: Chary, B. C.; Kim, S.; Shin, D.; Lee, P. H. Chem. Commun. 2011, 47, 7851-7853.

(22) For an alternative synthesis of halo-enol acetates, see: Chen, Z.; Li, J.; Jiang, H.; Zhu, S.; Li, Y.; Qi, C. Org. Lett. 2010, 12, 3262-3265.

(23) (a) Acetti, D.; Brenna, E.; Fuganti, C. Tetrahedron: Asymmetry 2007, 18, 488-492. (b) Caulkett, P. W. R.; Johnstone, C.; Mckerrecher, D.; Pike, K. G. (Astrazeneca Ab), WO2005044801 A1,
May 19, 2005. (c) Barkoczy, J.; Ling, I.; Balint, J.; Egri, G.; Kiss, V.; Fogassy, E. (Egyt Gyogyszervegyeszeti Gyar), WO2006013399 A1, February 9, 2006. (d) Csuzdi, E.; Sólyom, S.; Berzsenyi, P.; Andrási, F.; Sziráki, I.; Horváth, K.; Nagy, Z. (Teva Pharma), WO2008124075 A1, October 16, 2008.

(24) We have observed a single spot for both isomers of 30 by TLC using a wide diversity of mixtures of solvents.

(25) Auerbach, R. A.; Crumrine, D. S.; Ellison, D. L.; House, H. O. Org. Synth. 1974, 54, 49.

(26) We have repeated the synthesis of $3 \mathrm{~s}$ using different reaction conditions in the generation of the enolate, always obtaining low product yields. Currently we do not have an explanation for the different behavior shown by this reaction.

(27) (a) Ohashi, A.; Imamoto, T. Org. Lett. 2001, 3, 373-375. (b) Dolhem, F.; Johansson, M. J.; Antonsson, T.; Kann, N. J. Comb. Chem. 2007, 9, 477-486.

(28) For a similar observation in a Rh-catalyzed enamide hydrogenation, see: Burk, M. J.; Casy, G.; Johnson, N. B. J. Org. Chem. 1998, 63, 6084-6085. 